\title{
Halothane Blocks Low-Voltage-activated Calcium Current in Rat Sensory Neurons
}

\author{
Makoto Takenoshita" and Joe Henry Steinbach \\ Department of Anesthesiology, Washington University School of Medicine, St. Louis, Missouri 63110
}

\begin{abstract}
Although volatile anesthetic agents have been used clinically for many years, the mechanisms by which they act on the nervous system to produce anesthesia are not known. A possible site of action is the voltage-gated calcium-selective channel (Krnjevic and Puil, 1988). Accordingly, the action of the halogenated alkane anesthetic halothane on voltage-dependent $\mathrm{Ca}$ currents in neonatal rat sensory neurons was examined using whole-cell patch-clamp recordings. Halothane reversibly reduced the low-voltage-activated Ca current with an EC so $_{50}$ of about $100 \mu \mathrm{M}$. Similar effects were seen using a halogenated ether anesthetic (isoflurane) and in sensory neurons from adult rats. At higher concentrations, both halothane and isoflurane reduced the highvoltage-activated Ca current. Because low-voltage-activated $\mathrm{Ca}$ current has been postulated to be involved in the control of neuronal excitability and bursting (Llinas, 1988), this block may explain some of the clinical actions of volatile anesthetics.
\end{abstract}

The mechanisms by which volatile anesthetics produce clinical anesthesia are not understood. It is clear that at clinically relevant concentrations they have relatively little effect on conduction in peripheral axons, so it has been suggested that they act on some aspect of synaptic transmission (Larrabee and Posternak, 1952; Richards, 1983). More recent work has indicated that some voltage-gated membrane channels may be affected. In particular, neuronal voltage-dependent calcium currents have been implicated as a possible site of action. It has been suggested that volatile anesthetics depress evoked transmitter release by reducing $\mathrm{Ca}$ entry (Takenoshita and Takahashi, 1987), and measurements of evoked quantal content at Ia synapses onto motorneurons show a reduction (Kullmann et al., 1989). Furthermore, halothane has been found to reduce voltage-gated $\mathrm{Ca}$ current in hippocampal neurons (Krnjevic and Puil, 1988). There are several classes of voltage-gated $\mathrm{Ca}$ currents (Bean, 1989); the most distinct are the low-voltage-activated (LVA, or " $T$ ") current and the high-voltage-activated (HVA, or " $N$ " and/or

\footnotetext{
Received July 23, 1990; revised Nov. 26, 1990; accepted Dec. 19, 1990.

We thank A. Evers, J. Herrington, C. Lingle, E. McCleskey, M. Mamo, J. Schroeder, and R. Stern for advice during the course of this work, and A. Evers, J. Herrington, C. Kopta, C. Lingle, J. Nerbonne, J. Schroeder, and R. Stern for comments on the manuscript. This work was supported by NIH Grant NS 22356. M.T. was the Anesthesiology Research Unit postdoctoral fellow.

Correspondence should be addressed to J. H. Steinbach, Department of Anesthesiology, Washington University School of Medicine, Campus Box 8054, 660 South Euclid Avenue, St. Louis, MO 63110.

- Permanent and present address: Department of Anesthesiology, Osaka University Medical School, 1-1-50, 1-Chome, Fukushima, Fukushima-ku, Osaka 553, Japan.

Copyright (c) 1991 Society for Neuroscience 0270-6474/91/111404-09\$03.00/0
}

"L") current. LVA Ca current is activated at relatively negative membrane potentials $(-50 \mathrm{mV})$, is a transient current (inactivating in tens of milliseconds), and undergoes steady inactivation at negative membrane potentials (half-inactivation negative to $-50 \mathrm{mV}$ ). Although there is some debate about how many distinct types of HVA currents there are (see Bean, 1989), HVA Ca current is activated at more positive potentials $(-20 \mathrm{mV})$, is more maintained during a voltage-clamp pulse, and undergoes steady inactivation at more positive potentials than LVA current. The LVA and HVA Ca currents apparently fulfill different physiological roles in neurons. The LVA current is postulated to underlie depolarizing afterpotentials that can produce bursting behavior and may influence overall neuronal excitability. HVA current apparently carrics the $\mathrm{Ca}$ influx required for release of neurotransmitters (Llinas, 1988; Bean, 1989).

Because of the existing reports of an effect of volatile anesthetics on Ca current, we undertook a study of the effects of halothane (1,1,1-trifluorobromochloroethane) on Ca currents in rat dorsal root ganglion (DRG) cells. Halothane reversibly reduced LVA and HVA currents in these cells. Block of LVA current was especially potent, with a half-blocking concentration of about $100 \mu \mathrm{M}$.

A report of these findings has been published in abstract form (Takenoshita and Steinbach, 1990).

\section{Materials and Methods}

The methods were based on those described by Schroeder et al. (1990a). In brief, neonatal (0- or 1-d-old) Sprague-Dawley rats were anesthetized with halothane and decapitated. Dorsal root ganglia were dissected out, incubated in Hank's balanced salt solution, with no added $\mathrm{Mg}$ ions, and $25 \mu \mathrm{M} \mathrm{CaCl}_{2}$ containing collagenase $(0.1 \mathrm{mg} / \mathrm{ml}$; type CLS2, Worthington Biochemicals, Freehold, NJ) and trypsin $(0.1 \mathrm{mg} / \mathrm{ml}$; Gibco, Grand Island, NY) for $30 \mathrm{~min}$ at $37^{\circ} \mathrm{C}$. Ganglia were rinsed, then dispersed by trituration in growth medium minus NGF (see below). Drops of cell suspension in growth medium minus NGF were plated on collagencoated coverslips. Cells were allowed to settle for $2 \mathrm{hr}$ at $37^{\circ} \mathrm{C}$, then 2 $\mathrm{ml}$ of growth medium plus $50 \mathrm{ng} / \mathrm{ml} \beta-\mathrm{NGF}$ (isolated from mouse submaxillary glands and kindly provided by Dr. E. Johnson, Jr., Washington University School of Medicine) were added to the $35-\mathrm{mm}$ culture dish containing the coverslips. Dishes were returned to the incubator until use. Growth medium (Schroeder et al., 1990b) was composed of Ham's F12 (Gibco) with 5\% heat-inactivated horse serum, $44 \mathrm{~mm}$ glucose, 2 mm glutamine, $1 \% 100 \times$ minimum essential medium vitamin stock (Gibco), $100 \mathrm{U} / \mathrm{ml}$ penicillin, $100 \mu \mathrm{g} / \mathrm{ml}$ streptomycin, and $1 \%$ N3-additives concentrate (composed of $1 \mathrm{mg} / \mathrm{ml} \mathrm{BSA}, 20 \mathrm{mg} / \mathrm{ml}$ human transferrin, $3.2 \mathrm{mg} / \mathrm{ml}$ putrescine hydrochloride, $1.04 \mu \mathrm{g} / \mathrm{ml}$ sodium selenite, $2 \mu \mathrm{g} / \mathrm{ml}$ triiodothyronine, $1 \mathrm{mg} / \mathrm{ml}$ insulin, $1.25 \mu \mathrm{g} / \mathrm{ml}$ progesterone, and $4 \mu \mathrm{g} / \mathrm{ml}$ corticosterone).

Cells were studied at room temperature $\left(21-23^{\circ} \mathrm{C}\right)$ using the wholecell patch-clamp method between 12 and $20 \mathrm{hr}$ after dissociation. $\mathrm{Pi}$ pettes were prepared from KG33 borosilicate glass and coated with Sylgard 184 (Dow-Corning, Midland, MI) to within $50 \mu \mathrm{m}$ of the tip. Pipette resistances were between 3 and $5 \mathrm{M} \Omega$. Cells were chosen by 
morphology, because it was impossible to adequately space clamp a cell if it had visible processes. Once the whole-cell configuration had been gained, cells were accepted for further study if the series resistance read from the dial of an EPC-7 clamp amplifier (Medical Systems Corp., Greenvale, NY) was less than $10 \mathrm{M} \Omega$ and the series resistance could be compensated by $65 \%$ or more. The initial $5 \mathrm{~min}$ of a record were used to determine that the series resistance and the voltage-dependent $\mathrm{Ca}$ current were stable. At the end of this time, the peak inward current at $-30 \mathrm{mV}$ needed to be at least $100 \mathrm{pA}$. If these criteria were met, anesthetics were applied to the cell. In all, 25 neonatal cells were studied. The peak current at $-30 \mathrm{mV}$ (representative of low-voltage-activated or LVA Ca current) ranged from 100 to $1600 \mathrm{pA}(324 \pm 318 \mathrm{pA}$, mean $\pm \mathrm{SD}$ ). Normalized by cell capacitance, the mean was $15 \pm 15 \mathrm{pA} / \mathrm{pF}$. The peak current at $+20 \mathrm{mV}$ (representative of high-voltage-activated or HVA Ca current) ranged from 970 to $6930 \mathrm{pA}(2112 \pm 1580 \mathrm{pA}$ or $100 \pm 66 \mathrm{pA} / \mathrm{pF}$ ). The mean series resistance after compensation was calculated to be $1.6 \pm 0.6 \mathrm{M} \Omega(N=25)$. The calculated control error due to uncompensated series resistance was $0.4 \pm 0.3 \mathrm{mV}$ for peak LVA current and $3.1 \pm 2.0 \mathrm{mV}$ for peak HVA current. The maximal control error for HVA current was $9.4 \mathrm{mV}$ in an adult cell with 7800 pA of peak HVA current. There was no correlation between the efficacy of block of either LVA or HVA current with absolute current magnitude.

Voltage steps were applied to the cells using p-CLAMP software (Axon Instruments, Foster City, CA) and a 386-based computer. Data were filtered at 2-3 kHz with an 8-pole Bessel filter (Frequency Devices, Haverhill, MA) and sampled at $50-$ or $100-\mu \mathrm{sec}$ intervals. Leak and residual capacity currents were subtracted using a scaled average of 10 responses to hyperpolarizing steps (usually -80 to $-100 \mathrm{mV}$ ). Data were analyzed using several programs, including CLAMPAN (Axon Instruments), BnNFTrs and NFTrs (generously provided by C. Lingle, Washington University School of Medicine), and DELP (a program that fits multiple exponentials, generously provided by D. Maconochie, Washington University School of Medicine).

The recording solutions were those used by Schroeder et al. (1990a). The bath contained tetraethylammonium (TEA) $\mathrm{Cl}(135 \mathrm{~mm}), \mathrm{CaCl}_{2}$ (10 mm), and HEPES (10 mm); pH, 7.4 (adjusted with TEA-OH); 330 mOsm (adjusted with glucose). The pipette contained $\mathrm{CsCl}(100 \mathrm{mM})$, $\mathrm{MgCl}_{2}(2.5 \mathrm{~mm}), \mathrm{CaCl}_{2}(2.9 \mathrm{~mm})$ plus EGTA (10 mM; free Ca of 100 nM), HEPES (40 mm), ATP (1 mm), GTP (0.3 mm; Aldrich Chemical Co., Milwaukee, WI), and phosphocreatine ( $8.8 \mathrm{~mm}$ ); $\mathrm{pH}, 7.0$ (adjusted with $\mathrm{CsOH}$ ); 330 mOsm. All chemicals were obtained from Sigma Chemical Corp. (St. Louis, MO), unless otherwise indicated.

All experiments were done at room temperature $\left(21-23^{\circ} \mathrm{C}\right)$. Experiments were done in a small Plexiglas chamber (vol, $\sim 0.25 \mathrm{ml}$ ). The chamber was constantly perfused at about $1 \mathrm{ml} / \mathrm{min}$, either with bath saline or with bath saline containing anesthetic. Anesthetic solutions were applied from 60 -ml glass syringes connected through a Tefion fourway valve (Hamilton Co., Reno, NV). All plumbing was stainless-steel tubing (26-ga thin wall, Small Parts, Miami, FL), except for short flexible joints made from polyethylene tubing. Earlier failures had indicated the importance of a closed delivery system and the use of as little plastic as possible if accurate concentrations of anesthetic were to be delivered. Anesthetic solutions were made from saturated solutions prepared by equilibrating saline overnight at $20^{\circ} \mathrm{C}$ over halothane or isoflurane (saturated concentrations at $20^{\circ} \mathrm{C}$ are about $17 \mathrm{~mm}$ and $15 \mathrm{mM}$, respectively; see Firestone et al., 1986).

Anesthetic concentrations were determined at the end of a series of experiments by allowing solution to flow into the chamber for $2 \mathrm{~min}$, then collecting the contents of the chamber. Anesthetic concentrations were determined by gas chromatography using the methods published by Stern et al. (1989). The bath concentrations measured, in $\mu \mathrm{M}$, were as follows [given as median (range; number of determinations)]: $50 \mu \mathrm{M}$ nominal, $60(50-70 ; 8) ; 100 \mu \mathrm{M}, 105(100,110 ; 2) ; 250 \mu \mathrm{M}, 230(180$ $270 ; 6) ; 500 \mu \mathrm{M}, 480(280-630 ; 4) ; 1000 \mu \mathrm{M}, 850(710-850 ; 3)$. In the text, the nominal concentration is used; in the dose-response curves, the measured bath concentrations are shown except for a few points for which it was not measured.

The halothane used was purchased as Fluothane (Ayerst Laboratories, New York, NY); the isoflurane was Forane (Anaquest, Madison, WI). Isoflurane has no stabilizing or preservative agents added, but halothane has $0.01 \%(w / w$, or 0.00013 mole fraction) thymol added. The oil/water partition coefficients for halothane and thymol are comparable (thymol, $\sim 500$; halothane, $\sim 200$; Stecher, 1968), so it is likely that the final concentration of thymol in buffer is about $1 / 10,000$ that of the halothane. The maximal concentration of thymol in the halothane solutions used would then be about $0.2 \mu \mathrm{M}$. A related alcohol (menthol) reduces LVA currents in DRG neurons, but with an $\mathrm{EC}_{s 0}$ of $300 \mu \mathrm{M}$ (Swandulla et al., 1987).

Average values are given as mean \pm standard deviation (number of observations), unless specified otherwise. The significance of differences was estimated using the two-tailed $t$ test on unpaired observations of unequal variance. Confidence limits are given for parameters in individual fitted curves in some figure legends; these are given as nonlinear $90 \%$ confidence limits.

\section{Results}

The basic properties of the inward current seen in these cells and ionic conditions were identical to those reported by Schroeder et al. (1990a) and others (e.g., Bossu and Feltz, 1986; Carbone and Lux, 1987; Kostyuk and Shirokov, 1989). During depolarizing steps from a holding potential of $-80 \mathrm{mV}$ or more negative, the major currents were a transient inward current seen at potentials from $-50 \mathrm{mV}$ to about $-20 \mathrm{mV}$ and a larger and more maintained current seen at potentials positive to -20 $\mathrm{mV}$ (Fig. 1A). Previous workers have identified these currents as flowing through voltage-gated Ca-selective channels. In our hands, the currents were greatly reduced when external $\mathrm{Ca}$ was replaced with $\mathrm{Mg}$ ions and when $\mathrm{Cd}$ (3 $\mathrm{mm}$ ) was included in the external solution (data not shown). For these reasons, we consider these currents to be Ca currents. We also saw a transient outward current in some cells (e.g., Fig. 1). This current was seen at test potentials positive to $-20 \mathrm{mV}$. This current disappeared when cells were held more positive than $-40 \mathrm{mV}$, was insensitive to $1 \mu \mathrm{M}$ tetrodotoxin, and was not seen in all cells. We have not characterized this current further, but its presence may well have affected the rising phase of the inward Ca current. In a few cells that had very small $\mathrm{Ca}$ current but large transient outward current, it appeared that the outward current peaked by $10 \mathrm{msec}$ and decayed rapidly.

\section{Halothane reduces the peak amplitude of Ca current}

Our basic observation is illustrated in Figure 1: applications of halothane rapidly and reversibly reduced the amplitude of the Ca current in these cells. The effect appeared to be much stronger on the transient inward current evoked at relatively negative membrane potentials (LVA Ca current) than on current at positive test potentials (HVA Ca current; Figs. 1, 2).

To obtain a dose-response relationship, we defined a measure of the peak LVA channel current as the peak current measured at a test potential of $-30 \mathrm{mV}$ from a holding potential of -80 $\mathrm{mV}$, and the peak HVA current as the peak current measured at $+20 \mathrm{mV}$ from a holding potential of $-80 \mathrm{mV}$. As shown in Figure 3, halothane reversibly reduced both peak currents but had a much stronger effect on LVA current at a given concentration.

The effects of halothane developed as rapidly as chamber perfusion, within $30-60 \mathrm{sec}$. This is considerably more rapid than some reports, in which the time course of the effect was presumably slowed by slow equilibration of halothane with the preparation. Recovery from halothane could take several minutes (Fig. 3); the reason for the slower recovery than onset was not investigated further.

Because there is some instability in the amplitude of the $\mathrm{Ca}$ currents (Fig. 3), a qualitative dose-response relationship was constructed by taking the steady level reached during exposure to halothane and dividing it by the linearly interpolated value between the maximal surrounding control currents. The resulting dose-response relationship is shown in Figure 4. Halothane 

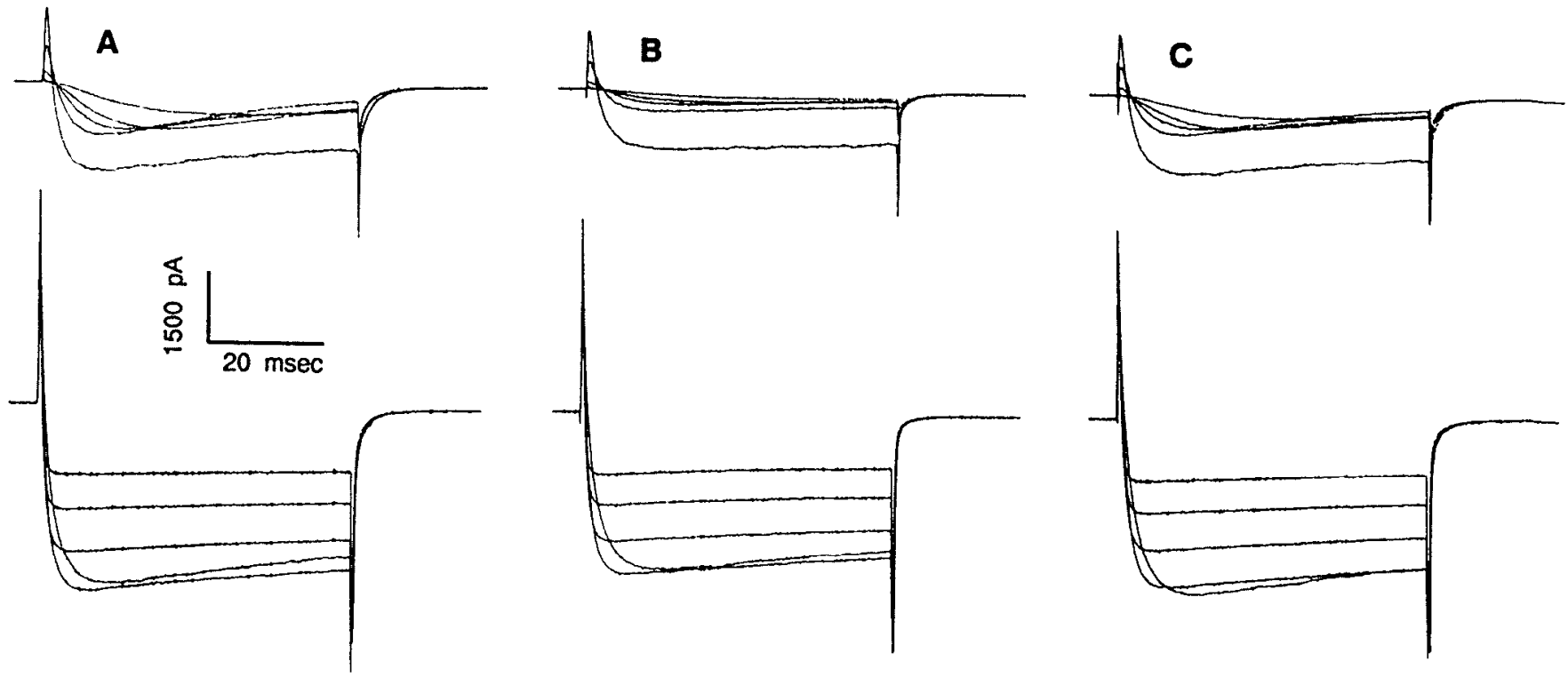

Figure 1. Halothane reduces LVA Ca current reversibly. Three sets of currents evoked in a neonatal rat DRG cell are shown: before halothane $(A)$, currents $4 \mathrm{~min}$ after starting application of $250 \mu \mathrm{M}$ halothane $(B)$, and currents $2 \mathrm{~min}$ after starting washout of halothane $(C)$. The upper traces in each panel show currents evoked at $-40,-30,-20,-10$, and $0 \mathrm{mV}$ (emphasizing the LVA current); the lower traces show currents at 10,20 , 30,40 , and $50 \mathrm{mV}$ (emphasizing the HVA current). The cell was held at $-80 \mathrm{mV}$, and the currents were evoked by 50 -msec voltage steps to test potentials from -40 to $+50 \mathrm{mV}$; steps were separated by 3 -sec intervals at the holding potential. The entire protocol was repeated at $1-3$-min intervals.

clearly has a more potent effect on LVA Ca current than on HVA Ca current.

It was possible that the relative weakness of the block of HVA current was because any effect of halothane depended on the

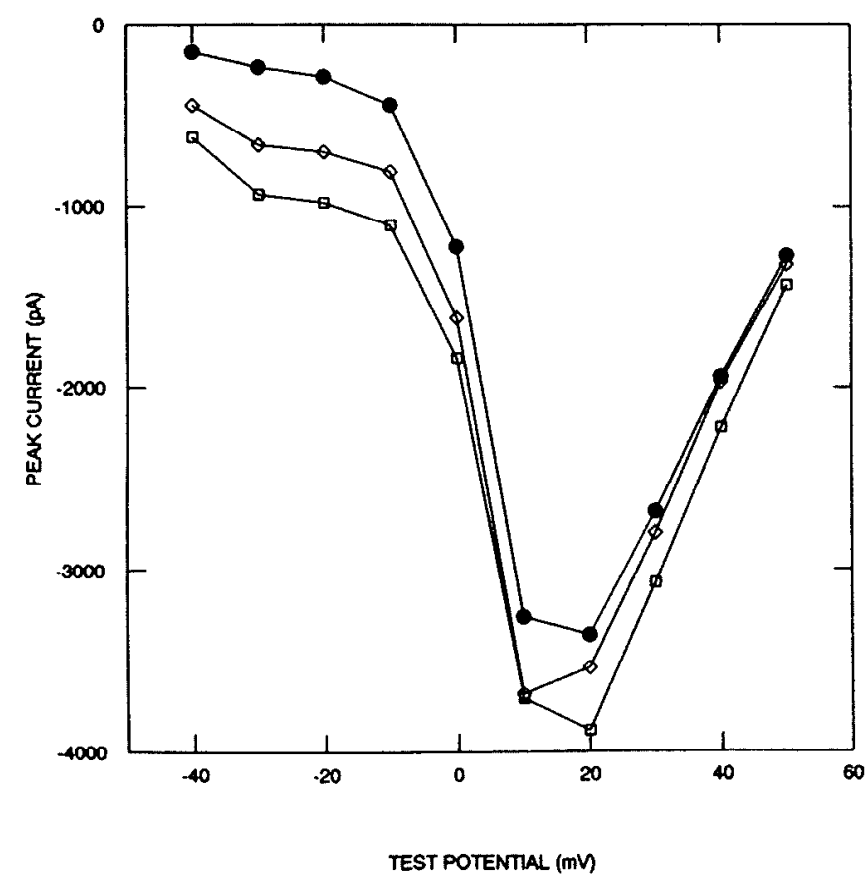

Figure 2. Current-voltage relationships in the presence and absence of halothane. Peak currents are plotted against test potential for the data traces shown in Figure 1 (open squares, control; solid circles, $250 \mu \mathrm{M}$ halothane; open diamonds, recovery). The shoulder of inward current seen at more negative test potentials is preferentially reduced by halothane. membrane potential. Therefore, in some cells the peak current at $20 \mathrm{mV}$ was measured from holding potentials of -50 or -30 $\mathrm{mV}$. With 500 or $1000 \mu \mathrm{M}$ halothane, there was no apparent effect of holding potential. The ratio of the fraction of HVA current remaining in halothane in steps from $-50 \mathrm{mV}$ to that in steps from $-80 \mathrm{mV}$ was $1.00 \pm 0.09$ (mean $\pm \mathrm{SD}$; nine applications), and the ratio for steps from $-30 \mathrm{mV}$ was $0.92 \pm$ 0.13 (eight applications). The ratios did not differ significantly from $1(p>0.1, t$ test). These observations also suggest that halothane affects inactivating and noninactivating components of HVA Ca current.

The dose-response curve for LVA Ca current is not well described by a simple binding isotherm; the line in Figure $4 A$ is a plot of the Hill equation with an apparent $K_{d}$ of $100 \mu \mathrm{M}$ and a Hill coefficient of 0.4 . There are several possible explanations for such a flat dose-response curve. One is that there is some contribution of HVA current activated at $-30 \mathrm{mV}$, which is not as strongly affected by halothane, and hence would contribute a portion of "LVA" current that would not be blocked. In some cells, there was more than $100 \mathrm{pA}$ of inward current at a test potential of $-40 \mathrm{mV}$. In these cells, there was no significant difference in the efficacics of block at $-30 \mathrm{mV}$ and $-40 \mathrm{mV}$ (ratio of fractions remaining at $-30 \mathrm{mV}$ to that at $-40 \mathrm{mV}$, $1.1 \pm 0.5 ; 12$ applications of 500 or $1000 \mu \mathrm{M}$ halothane). In four applications, there was a larger fraction of current remaining in steps to $-30 \mathrm{mV}$, whereas in eight applications, there was a smaller fraction. A second possible explanation is that, in some cases, recovery of the LVA current appeared to be protracted (Fig. 3). It is possible that the "control" current amplitude was underestimated for applications after the first one. Because anesthetics were usually applied at increasing doses, this could produce an apparent flattening and would also increase the scatter. A third explanation for the flat dose-response curve is that the maximal block is not complete and might differ between cells (e.g., Fig. 3). 

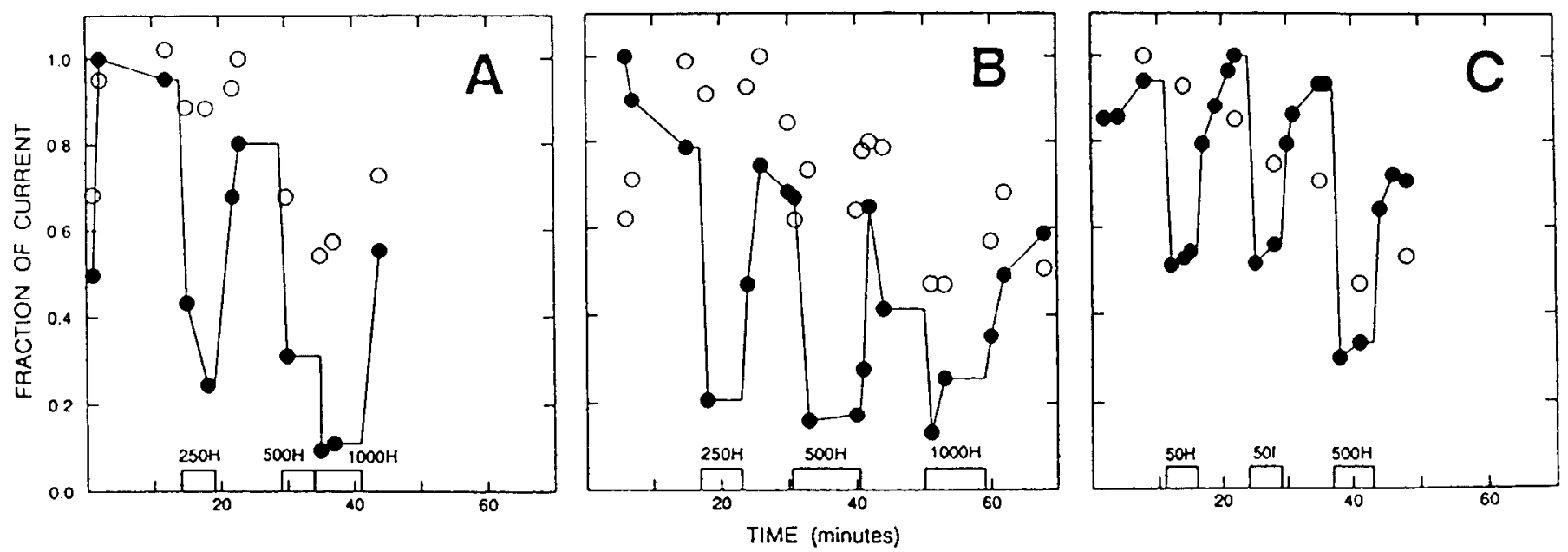

Figure 3. Halothane reduces Ca currents reversibly. Peak currents at test potentials of $-30 \mathrm{mV}$ (solid circles and lines, LVA) and $+20 \mathrm{mV}$ (open circles, HVA) are shown as a function of time during the whole-cell recording. Halothane was applied to the cells as indicated on the abscissa. $A$ shows data from the cell illustrated in Figures 1 and $2 ; B$ shows data from another neonatal cell. $C$ shows data from an adult DRG cell exposed to $50 \mu \mathrm{M}$ halothane $(50 \mathrm{H})$ and isoflurane ( $50 \mathrm{I}$ ). Lines have been drawn to connect LVA currents; to emphasize the timing of anesthetic applications, the lines are drawn at the level of the preceding current until the time of application (flat segments and cusps without data points). Note that the effect on LVA current may saturate at less than complete block, and the maximal block may differ among cells. LVA and HVA current amplitude showed some changes with time, both decreases and increases. The maximal currents seen were $A$ : LVA, -980 pA; HVA, -3800 pA; $B$ : LVA, -145 pA; HVA, -1950 pA; C: LVA, -560 pA; HVA, -2540 pA.

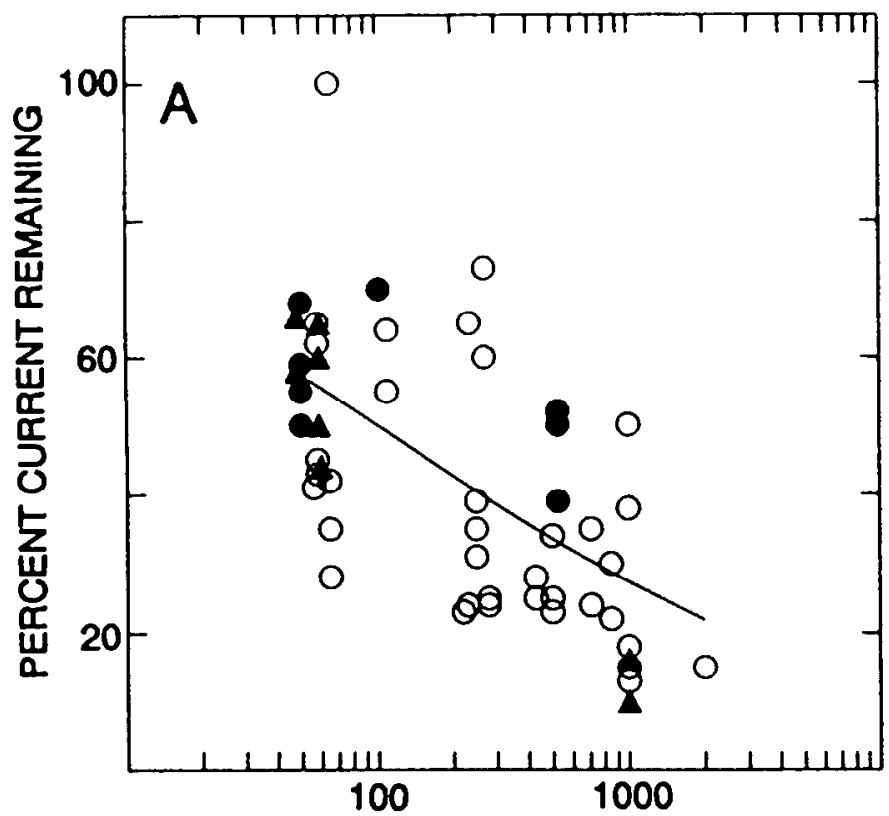

[HALOTHANE], micromolar

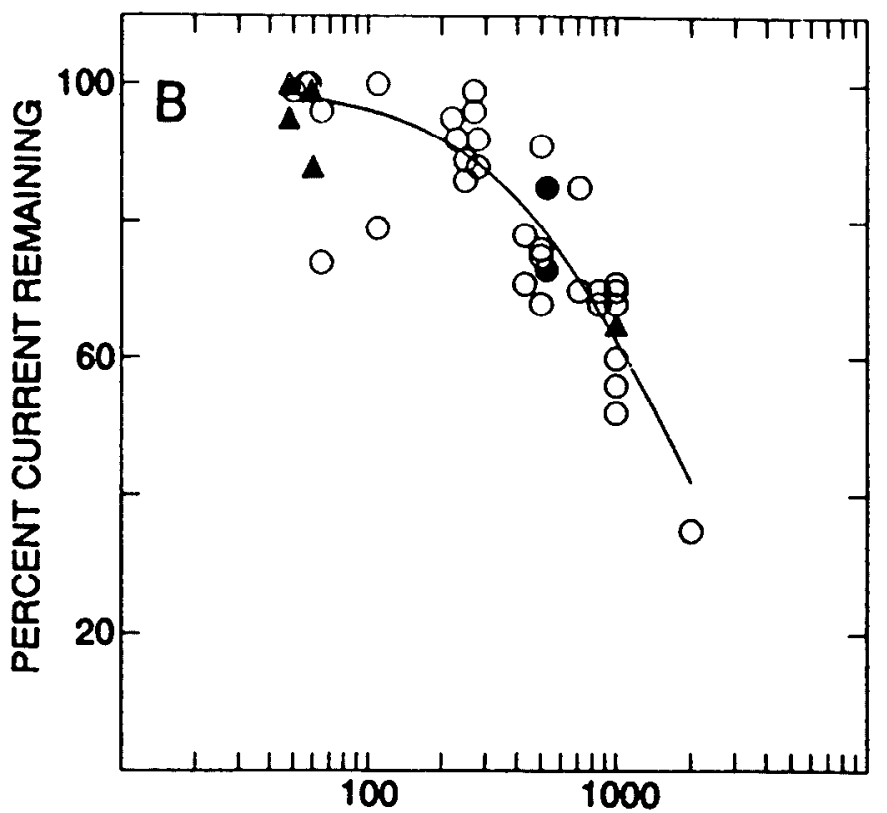

[HALOTHANE, micromolar

Figure 4. Halothane reduces LVA Ca current at lower concentrations than HVA current. The percentage of control current remaining in the presence of anesthetic is plotted against anesthetic dose for peak currents elicited at $-30 \mathrm{mV}(A$, LVA $)$ and $+20 \mathrm{mV}(B$, HVA). Most data were obtained with halothane applied to neonatal cells (open circles); data obtained with isoflurane applied to either adult or neonatal cells (solid triangles) and with halothane applied to adult cells (solid circles) are also shown. The lines through the points show fits of the Hill equation $Y(X)=1 /[1+$ $\left.\left(X / K_{n}\right)^{n}\right]$, where $Y$ is percent of current remaining and $X$ is halothane concentration. Curves were fit to data obtained with halothane applied to neonatal cells (open circles). Fitting was done using the NFrTs program; the values for the curves shown are LVA current, $K_{D}=100 \pm 40 \mu \mathrm{M}, n=$ $0.4 \pm 0.1$; HVA current, $K_{D}=1500 \pm 260 \mu \mathrm{M}, n=1.2 \pm 0.2$. Altogether, data are shown for 25 neonatal cells exposed to 45 applications of anesthetic, and 4 adult cells exposed to 10 applications. 
A

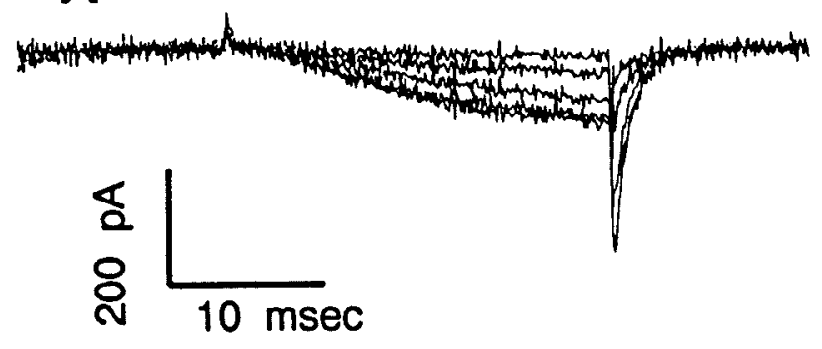

8

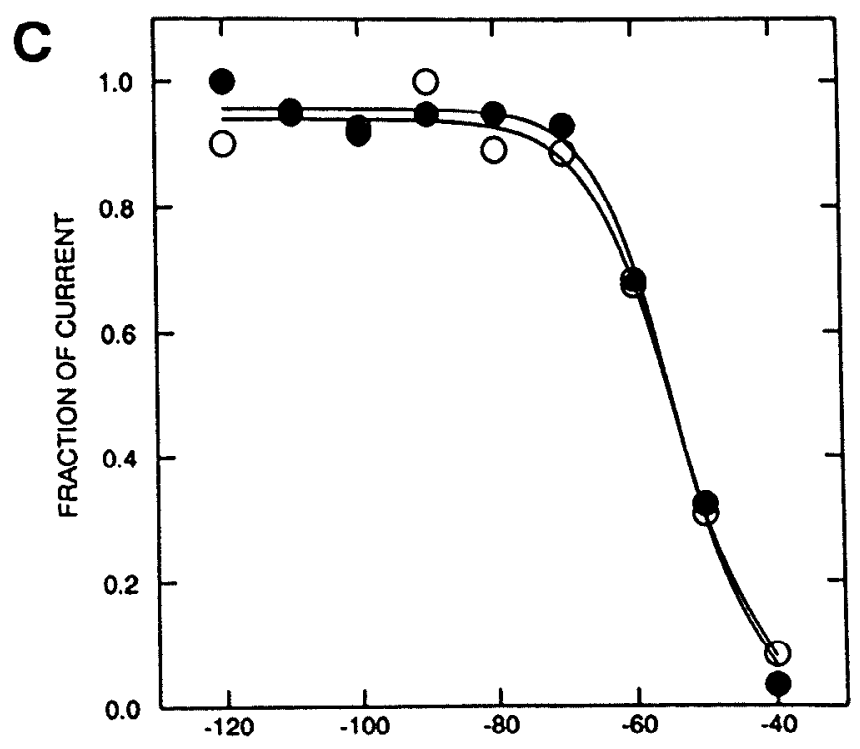

CONDITIONING POTENTIAL (mV)

Figure 5. The voltage dependence of steady-state inactivation of LVA Ca current is not altered by halothane. Currents elicited at $-40 \mathrm{mV}$ in an adult DRG cell after conditioning at different potentials are shown in the two left panels $(A$, control; $B, 1$ min after start of application of $50 \mu \mathrm{M}$ halothane; conditioning potentials for traces shown are $-100,-80,-60,-50$, and $-40 \mathrm{mV}$ ). A plot of fraction of maximal current against conditioning potential $(C)$ shows no shift in the presence of halothane (solid circles), though the maximal current was reduced to $67 \%$ of control (see $A, B)$. The lines in $C$ show fits of the equation $Y(X)=F /\left(1+\exp \left[-\left(X-V_{\mathrm{so}}\right)\right] / k\right)$, where $Y$ is the observed fraction of maximal current, $X$ is conditioning potential, $F$ is the fitted maximal current, $V_{50}$ is the potential at which current is reduced $50 \%$, and $k$ is a slope factor. The curves shown have values $V_{30}=-54 \mathrm{mV}, k=-6.0 \mathrm{mV}$ (control) and $V_{50}=-54 \mathrm{mV}, k=-5.5 \mathrm{mV}$ (halothane), with confidence limits of $\pm 2 \mathrm{mV}$ for $V_{30}$ and $+1 \mathrm{mV}$ for $k$. The cell was held at $-100 \mathrm{mV}$. At 3-sec intervals, a conditioning pulse lasting 1 sec was applied; conditioning pulses were to potentials of -120 to $-40 \mathrm{mV}$ in $10-\mathrm{mV}$ steps. At the end of each conditioning pulse, the membrane potential was stepped to - $100 \mathrm{mV}$ for $15 \mathrm{msec}$, then LVA current was evoked at $-40 \mathrm{mV}$ with a $25-\mathrm{msec}$ pulse. At the end of the test pulse, the potential was returned to $-100 \mathrm{mV}$.
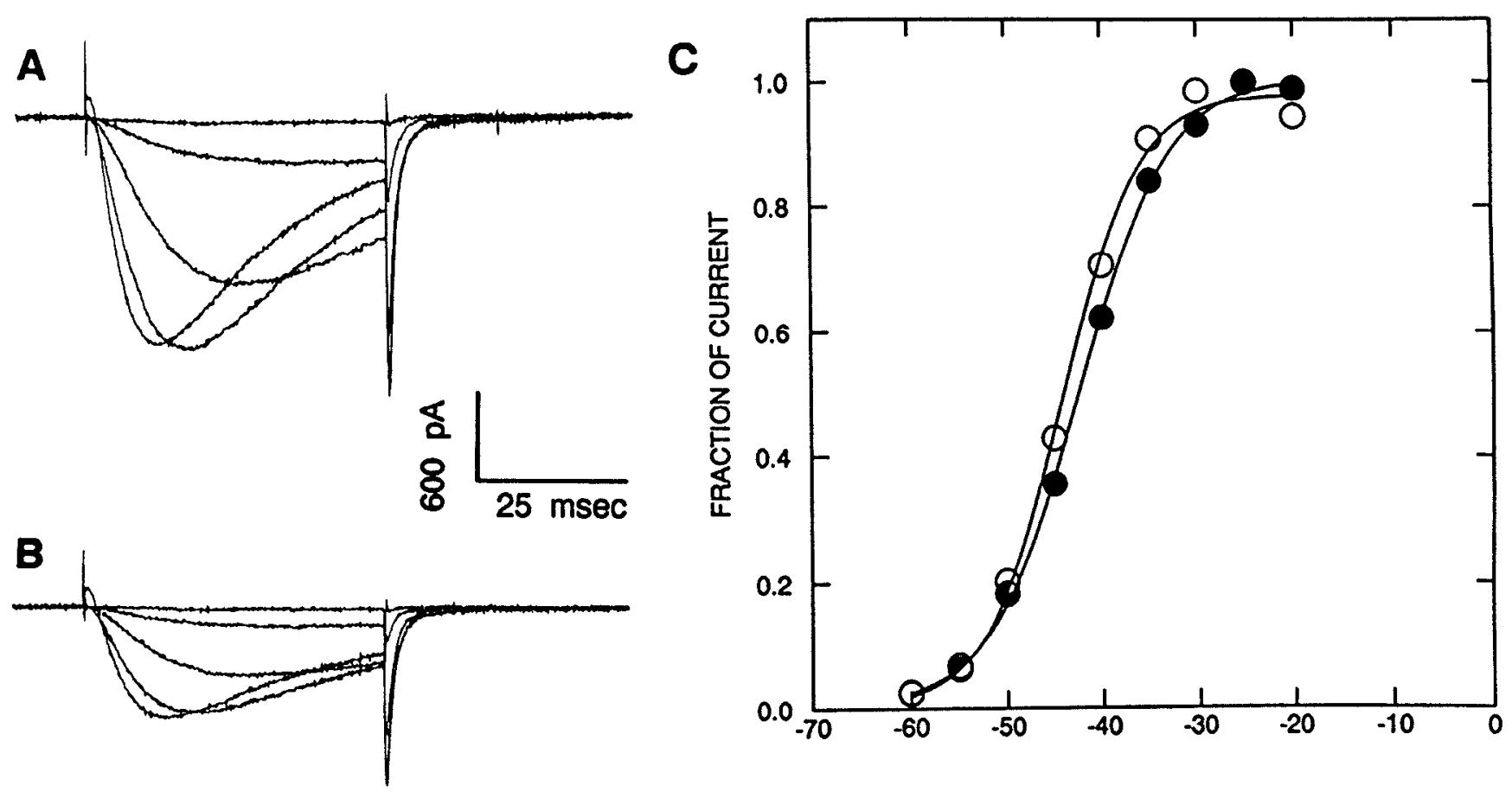

TEST POTENTIAL (mV)

Figure 6. Halothane does not affect the voltage dependence of activation of LVA Ca current at negative potentials. LVA Ca current was elicited in a neonatal DRG cell in control solution $(A)$ and $2 \mathrm{~min}$ after start of application of $50 \mu \mathrm{M}$ halothane $(B)$. Traces are shown of currents elicited at potentials of $-60,-50,-40,-30$, and $-20 \mathrm{mV}$. $C$ shows normalized peak $I-V$ curves for currents in control solution (open circles) and in the presence of halothane (solid circles). The lines drawn are fits of the Boltzmann relationship, with values for $V_{s 0}$ of $-44 \pm 1 \mathrm{mV}$ (control) and -44 $\pm 0.4 \mathrm{mV}$ (halothane), and for $k$ of $4 \pm 1 \mathrm{mV}$ (control) and $5 \pm 0.5 \mathrm{mV}$ (halothane). The cell was held at $-100 \mathrm{mV}$. Every $3 \mathrm{sec}$, a 50 -msec test pulse was applied to potentials of -60 to $-15 \mathrm{mV}$ in $5-\mathrm{mV}$ increments. 
The effect of halothane does not involve a change in the voltage dependence of LVA Ca-channel inactivation

Halothane has been reported to reduce peak sodium current amplitudes elicited from a given holding potential by shifting the steady-state inactivation curve towards more negative potentials, so fewer sodium channels are available to be opened at a given holding potential (Ikemoto et al., 1986; Ruppersberg and Rüdel, 1988). To test whether this possible mechanism was likely, we held cells at $-100 \mathrm{mV}$, then applied 1 -sec conditioning pulses to potentials from -120 to $-40 \mathrm{mV}$. As can be seen in Figure 5, the currents elicited at a test potential of $-40 \mathrm{mV}$ were equally depressed by halothane at all conditioning potentials. The dependence of steady-state inactivation on conditioning voltage was examined by fits of the Boltzmann equation (see Fig. 5 caption). In all, 19 inactivation curves were obtained in the absence of halothane (nine neonatal and two adult cells) and gave values for the half-inactivation voltage $\left(V_{50}\right)$ of -61 $\pm 4 \mathrm{mV}$ and steepness parameter $(k)$ of $-7.0 \pm 1.2 \mathrm{mV}$. Curves in the presence of halothane were obtained from one adult and four neonatal cells, at concentrations ranging from 50 to 500 $\mu_{\mathrm{M}}$ halothane (nine curves in all). There was no negative shift in inactivation: the mean $V_{s 0}$ value was $-57 \pm 4 \mathrm{mV}(p<0.05)$. The steepness parameter was slightly increased to $-7.8 \pm 2.0$ $\mathrm{mV}(p<0.1)$, which would result in a slight flattening of the inactivation curve. There was no obvious dependence of either parameter on halothane concentration, comparing across concentrations for a single cell or for the entire data set.

\section{The voltage dependence of LVA current activation is apparently not altered by halothane}

The voltage dependence of peak LVA current appeared to be little affected by halothane. Test pulses to potentials in the range of -60 to $-15 \mathrm{mV}$ (to activate preferentially the LVA Ca current) resulted in peak $I-V$ curves that were depressed but not shifted along the voltage axis (Fig. 6). For descriptive purposes, a Boltzmann equation was fit to the normalized peak $I-V$ curves. The $V_{50}$ value was not affected by halothane; in control saline, the mean $V_{s 0}$ was $-38 \pm 3 \mathrm{mV}(N=18$ curves in seven cells), whereas in halothane $(50-500 \mu \mathrm{M})$, the mean was $-38 \pm 4 \mathrm{mV}$ $(N=9$ in five cells). Similarly, the mean steepness was $5.5 \pm$ $0.8 \mathrm{mV}$ for control curves and $6.1 \pm 1.3 \mathrm{mV}$ in the presence of halothane. Values obtained in the presence of halothane did not differ signficantly from those in control solutions $(p>0.1)$. These observations indicate that the voltage dependence of peak LVA current is not shifted by halothane, even though the amplitude is reduced.

Some preliminary examination of LVA current kinetics was made, to determine whether halothane altered activation or inactivation rates. Inspection of the traces in Figure $7 A$ indicates that there is no major change in the kinetics of the tail currents seen upon repolarization to $-100 \mathrm{mV}$. Tail currents from a test potential of $-30 \mathrm{mV}$ were examined, to avoid contamination with HVA currents. The tail currents decayed along a time course that was well described as the sum of two exponentials; the major component ( $>85 \%$ of the amplitude) had a time constant of about $2 \mathrm{msec}$, while the minor component was smaller and slower (about $10 \mathrm{msec}$; see Fig. $7 A$; similar records are shown by Carbone and Lux, 1987). The major component has a time constant close to that reported previously for deactivation rates of LVA currents in rat DRG cells (Carbone and Lux, 1987; Kostyuk and Shirokov, 1989), so the effect of halothane on it
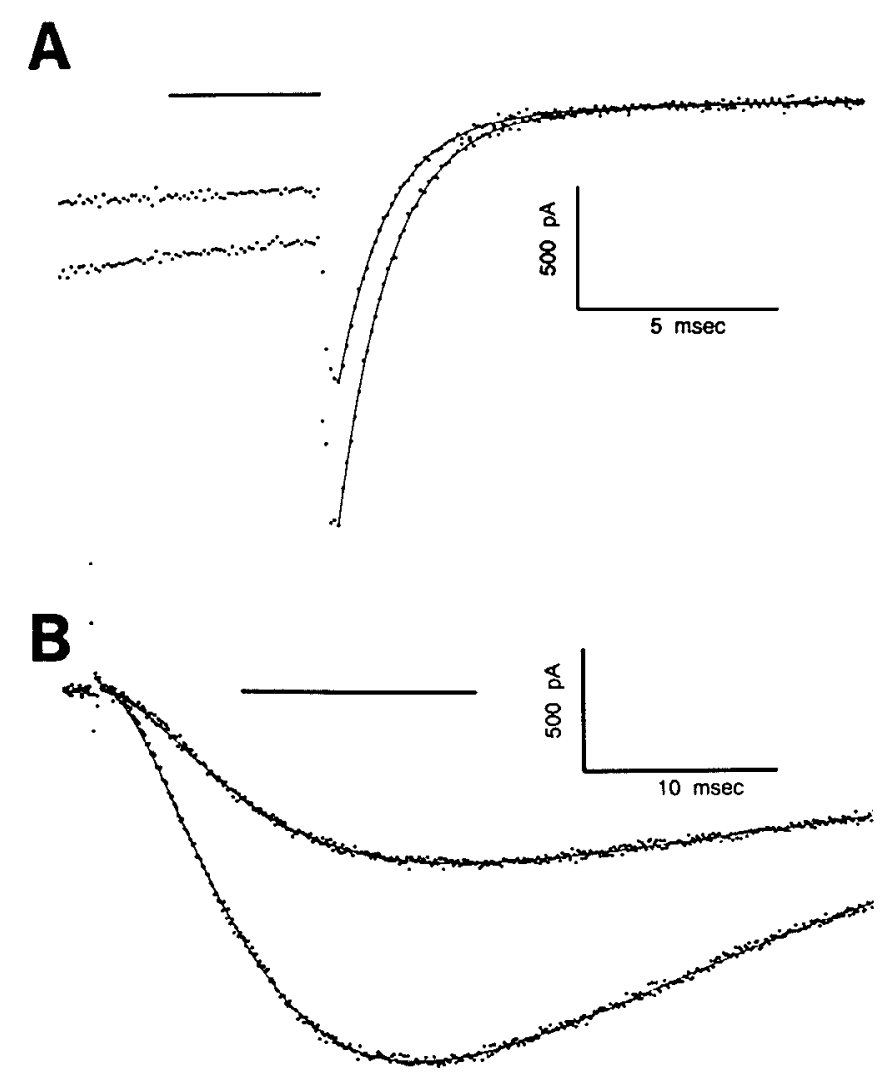

Figure 7. Halothane does not affect activation kinetics. $A$ shows superimposed traces of the end of the current evoked at $-30 \mathrm{mV}$ followed by the tail currents recorded when the cell was repolarized to $-100 \mathrm{mV}$ in control (larger current) and halothane-containing (smaller current) solution. The horizontal line indicates the zero current level. The complete traces for these tail currents are shown in Figure $6 A, B$. Superimposed on the data points are fits of the sums of two exponentials in each case. The values for the curves shown are as follows: control slow component amplitude, $-89 \pm 6 \mathrm{pA}$ (time constant, $10 \pm 1 \mathrm{msec}$ ); control faster component amplitude, $-1634 \pm 25 \mathrm{pA}$ (time constant, $1.3 \pm 0.03 \mathrm{msec}$ ); halothane slow component amplitude, $-101 \pm 6 \mathrm{pA}$ (time constant, $8 \pm 0.6 \mathrm{msec}$ ); halothane faster component amplitude, $-1055 \pm 19 \mathrm{pA}$ (time constant, $1.2 \pm 0.02 \mathrm{msec}$ ). Note that the reduction of tail current amplitude is comparable to that of the peak current. $B$ shows the initial time course of the currents evoked at -30 $\mathrm{mV}$ in control (larger current) and halothane-containing (smaller current) solutions. Again, complete traces are shown in Figure $6 A, B$. Superimposed on the traces are fits of an $m^{2} h$ Hodgkin-Huxley equation. The values for the fits shown are control: amplitude, $-3385 \pm 8 \mathrm{pA}$; $\tau_{m}, 7.6 \pm 0.3 \mathrm{msec} ; \tau_{h}, 28 \pm 1 \mathrm{msec}$; halothane: amplitude, $-1270 \pm$ $4 \mathrm{pA}, \tau_{m}, 7.4 \pm 0.4 \mathrm{msec} ; \tau_{h}, 41 \pm 0.2 \mathrm{msec}$. Note that the theoretical amplitude is more strongly reduced by halothane than is the peak amplitude, because the calculated effect of the inactivation on the peak current is reduced when the rate of inactivation is slowed.

was examined. At $-80 \mathrm{mV}$, the time constant in control solution was $2.5 \pm 0.6 \mathrm{msec}(N=14$ currents in six cells), while in the presence of halothane $(50-500 \mu \mathrm{M})$, the time constant was 2.37 \pm 0.5 (nine currents in five cells). At $-100 \mathrm{mV}$ the time constant in control solution was $1.63 \pm 0.3 \mathrm{msec}$ (14 currents in five cells), and in halothane was $1.56 \pm 0.4 \mathrm{msec}$ (eight currents in four cells). There was no effect of halothane on the deactivation time constants ( $p>0.5$ in each case). However, the amplitude of the tail current was reduced by halothane essentially as much as the peak inward current. The ratio of the fraction of tail current amplitude remaining in the presence of halothane to the remaining fraction of peak current amplitude in that record was 
$1.1 \pm 0.1$ at $-80 \mathrm{mV}$ (nine applications to five cells) and 1.2 \pm 0.4 at -100 (eight applications to four cells; $p>0.05$ in both cases). Hence, halothane apparently has no effect on deactivation rates of LVA channels at negative potentials, but does reduce the tail current amplitude to a similar extent as the inward current at $-30 \mathrm{mV}$.

The analyses so far indicate that the voltage dependence of the steady-state inactivation, the voltage dependence of the peak activation, and the deactivation rate for LVA current are not altered by halothane. However, inspection of the traces in Figures 1 and 6 indicates that some changes in the time course of the current do occur (e.g., traces at $-30 \mathrm{mV}$ ). The time to peak is slightly increased, and the extent of inactivation is decreased, so the current appears to be less peaked. A model-dependent preliminary analysis was made of the waveforms at $-30 \mathrm{mV}$ using a Hodgkin-Huxley equation. Initial trials indicated that either $m^{2} h$ or $m^{3} h$ forms described the data adequately, and the $m^{2} h$ form was used (Fig. $7 B$ ). These analyses suggested that the major change was an increase in the time constant for macroscopic inactivation $\left(\tau_{h}\right)$, with little change in the time constant for macroscopic activation $\left(\tau_{m}\right)$. At $-30 \mathrm{mV}$, the mean $\tau_{m}$ in control solution was $9.2 \pm 2 \mathrm{msec}$ ( 15 records from seven cells), while in halothane $(50-500 \mu \mathrm{M})$, the mean was $7.4 \pm 2.3 \mathrm{msec}$ (nine records from seven cells). The difference is marginally significant $(0.05<p<0.1)$, but is probably real because in all seven cells the time constant was shorter in the presence of halothane. The mean $\tau_{h}$ s were $64 \pm 36 \mathrm{msec}$ (control) and 105 $\pm 44 \mathrm{msec}$ (halothane). This difference is significant at $0.025<$ $p<0.05$, and again the shift was seen in all seven cells examined. There was no obvious concentration dependence to the lengthening, though this might well reflect the limited data set. The small change in activation rate is in agreement with the absence of a change in deactivation rate found in the analysis of tail currents. No mechanistic interpretation of these macroscopic rates can be made, especially as they were derived in the context of a particular kinetic model. However, the changes are in the opposite direction to those that would be expected to reduce the peak current.

Overall, these analyses have not found major effects of halothane on the kinetics of LVA currents that explain the reduction in peak amplitude.

\section{Isoflurane has similar effects}

Isoflurane is a halogenated volatile anesthetic, but is an ether rather than an alkane. To determine whether other volatile anesthetics also affected LVA Ca current, we tested isofiurane on some cells. Although too few experiments were done to estimate accurately the potency of isoflurane, its ability to block LVA Ca currents is clearly apparent at concentrations as low as 50 $\mu \mathrm{M}$ (Figs. 3, 4).

\section{Halothane blocks LVA current in DRG cells from adult rats}

In a single experiment, we examined the effects of halothane and isoflurane on cells from adult rat DRG cells (the cells were kindly provided by M. Mamo, Washington University School of Medicine). The effects of halothane and isoflurane on four cells in this preparation were indistinguishable from effects on neonatal cells (Figs. 3-5).

\section{Discussion}

Our results indicate that halothane and isoflurane act on rat sensory neurons to reduce the amplitude of LVA Ca current.
The kinetic mechanism by which the LVA current is reduced is not known. The data on the voltage dependences of activation and inactivation are consistent with the idea that either some channels are completely removed from the activatable pool, or the single-channel conductance is reduced. However, there is some indication that the rate of channel inactivation is affected by halothane. Final determination of the mechanism will require additional expcriments designed specifically to address this question.

Because LVA current is more effectively blocked than HVA current, some selective action of halothane is implied. This could result from an effect on a nonchannel protein; for example, the LVA channel could be more sensitive to alterations in a modulatory protein or subsequent steps in a pathway. Such selective modulation is known to occur in rat DRG cells, because phorbol 12-myristate 13-acetate reduces LVA current amplitude while leaving HVA current relatively unaffected (Schroeder et al., 1990a; but see Gross and MacDonald, 1989). Alternatively, the local membrane environment around the LVA channel could be preferentially perturbed, the LVA channel protein might be more sensitive to perturbation, or anesthetic may interact preferentially with the LVA channel protein. None of these alternatives are favored by the present results.

Both halothanc and isoflurane blocked LVA current in almost all cells tested (one cell tested only with $50 \mu \mathrm{M}$ halothane showed no block). The maximum block is not known; $90 \%$ block was seen in some cells. However, the dose-effect curve was very poorly described by a simple binding isotherm, showing a Hill coefficient of 0.4 . This observation cannot be given any mechanistic interpretation, because the reason for such a flat curve is not known. Two of the possibilities are that the currents are contaminated by some HVA current (which is relatively insensitive), or that the maximal block is not complete. The possibility of incomplete block is raised by some previous pharmacological studies of LVA currents using drugs that are relatively specific for block of LVA over HVA Ca current. The anti-petit mal seizure drugs ethosuximide and dimethadione reduce the amplitude of LVA current in thalamic relay neurons (Coulter et al., 1989b). In this case, the maximal inhibition is only about $40 \%$ (with an $\mathrm{EC}_{50}$ of $200 \mu \mathrm{M}$ ) and about one-quarter of the cells tested had LVA current that was insensitive to the drugs. Amiloride can fully block LVA current in N1 8 neuroblastoma cells, with an $\mathrm{EC}_{50}$ of $30 \mu \mathrm{M}$ (Tang et al., 1988). Amiloride also blocks LVA current in adult rat DRG neurons (Carbone et al., 1990a), but is less effective against LVA current in human IMR32 neuroblastoma cells (Carbone et al., 1990b) and is ineffective on LGN neurons (Suzuki and Rogawski, 1989). These pharmacological results suggest that LVA current may be heterogeneous, between cell types and possibly even within a single cell. For this reason, further experiments will be required before the effects of halothane seen in DRG cells can be generalized to other neurons.

The half-blocking concentration of halothane for LVA current is about $100 \mu \mathrm{M}$ for neonatal DRG neurons. The inhaled concentration necessary to anesthetize a rat is about $1.2 \%(\mathrm{v} / \mathrm{v}$; Evers et al., 1986). This vapor pressure corresponds to an equilibrium concentration in saline of about $0.3 \mathrm{~mm}$ (at $37^{\circ} \mathrm{C}$ ), which gives an estimate of the concentration of free anesthetic in biological fiuids, though the effective concentration in the nervous system is not known. Caution must be exercised in extrapolating the effects observed in this report at room temperature to those seen at body temperatures, because it is known that the kinetics 
and modulation of Ca currents can be strongly temperature dependent (Cavalie et al., 1985; Schroeder et al., 1990a). However, the block of LVA current in rat DRG cells clearly occurs at concentrations of anesthetic achieved during surgical procedures.

Although HVA currents were less sensitive than LVA currents, the mean block at nominal $250 \mu \mathrm{M}$ halothane was $8 \pm$ $4 \%$ (eight applications), and at $500 \mu \mathrm{M}, 23 \pm 8 \%$ (eight applications). Thus, significant block of HVA currents can occur in these cells over the effective concentration range.

The physiological role of LVA currents is thought to be twofold. LVA current can underlie the depolarizing afterpotential that results in bursting by neurons (Llinas, 1988; Suzuki and Rogawski, 1989; White et al., 1989). Also, LVA current can affect the overall excitability of a neuron because it activates at a more negative potential than voltage-gated sodium current. Hence, LVA current activation can serve to initiate a full-blown action potential from relatively negative membrane potentials (Llinas and Yarom, 1981; Coulter et al., 1989a). Block of LVA currents would therefore be expected to reduce the bursting activity and excitability of some neurons. Because some adult rat DRG neurons show bursting activity driven by LVA currents (White et al., 1989), some analgesic effect of halothane might result from block of these currents. Furthermore, neuronal bursting has been associated with seizure activity, and some antiseizure drugs have been shown to reduce LVA currents (Coulter et al., 1989b).

The high sensitivity of LVA Ca current in these cells is surprising, because previous studies of voltage-gated currents have indicated that clinically used concentrations of volatile anesthetics have little or no effect (Haydon and Urban, 1983, 1986; Ikemoto et al., 1986; Ruppersberg and Rüdel, 1988; Herrington et al., 1990). Indeed, major possible neuronal targets of volatile anesthetics have been proposed to be GABA receptors (Nicoll, 1972) and $\mathrm{K} *$-selective channels other than classical voltagesensitive ones (Nicoll and Madison, 1982; Franks and Lieb, 1988). Inhibitory postsynaptic currents mediated by GABA are prolonged up to twofold by volatile anesthetics, though most studies have used concentrations higher than clinical (Scholfield, 1980; Gage and Robertson, 1985). Halothane potentiates responses to low doses of GABA, but markedly enhances the rate and extent of desensitization produced by higher concentrations (Nakahiro et al., 1989). A recent paper compared responsiveness of cortical neurons to several neurotransmitters in the absence and presence of halothane and isoflurane (Puil and El-Beheiry, 1990). In these experiments, the most sensitive response was an excitatory one mediated by muscarinic receptors, which was strongly blocked at clinically effective concentrations of anesthetics. This observation may be related to the recent report that halothane and isoflurane depress an ATP-stimulated mixed Na-K conductance (" $I_{H}$ ") in bullfrog sensory neurons (Tokimasa et al., 1990). Several reports have been made that volatile anesthetics produce a membrane hyperpolarization by an increase in $\mathrm{K}$-selective conductances in vertebrate (Nicoll and Madison, 1982; Berg-Johnsen and Langmoen, 1987) and snail (Franks and Lieb, 1988) neurons, though halothane actually blocks the resting $\mathrm{K}$ conductance in squid axon (Haydon et al., 1988). It is clear that the conductance in snail neurons is affected strongly at clinically used concentrations; complete dose-response data are not yet available for other cells. The block of $I_{H}$ mentioned earlier results in a membrane hyperpolarization in cells in which this conductance is active, but one associated with a decrease in membrane conductance. All in all, anesthetics have relatively specific effects on several membrane conductance systems. The aggregate effect on a given cell will depend on the mix of conductances expressed and the concentration of anesthetic applied. The block of LVA Ca currents in rat sensory neurons occurs at concentrations comparable to or less than those required for other actions of anesthetics on membrane conductances.

It seems unlikely that an effect on LVA Ca current can explain the mechanism of action of volatile anesthetics. As just described, other actions of anesthetics are known. Also, the reported reduction in quantal content at Ia synapses (Kullmann et al., 1989) is unlikely to be associated with a reduction in LVA Ca current. A more likely target is the HVA current thought to be involved in evoked transmitter release (Hirning et al., 1988; Holz et al., 1988), and the reduction in Ca current reported by Kmjevic and Puil (1988) is most likely an effect on HVA current. Finally, some drugs that affect LVA currents do not appear to act as anesthetics (e.g., ethosuximide; Coulter et al., 1989b). Further work will be required to delineate which effect, or combination of effects, of volatile agents is required to produce general anesthesia.

Because of the effects on quantal release already mentioned, it was expected that halothane would affect HVA Ca current, so the relative insensitivity seen came as a surprise. However, some results suggest that the effects of halothane on Ca currents may differ between cells. Recent work with the clonal pituitary cell line GH3 has shown that halothane has a strong blocking effect on the HVA current ( $500 \mu \mathrm{M}$ blocks plateau HVA by $50 \%$ ) and a weaker action on the LVA current in those cells $(50 \%$ block at $1300 \mu \mathrm{M}$; Herrington et al., 1990). Furthermore, in adult dog ventricular myocytes, halothane is able to reduce both the LVA and HVA Ca current with equal potency (reduction to about 0.67 at $450 \mu \mathrm{M}$; Eskinder et al., 1990).

In conclusion, the present results show that halothane and isoflurane block the LVA Ca current in rat DRG cells. The block appears to be present in all cells and is pronounced at clinically effective concentrations of these anesthetics. It is not known whether this effect can underlie the mechanism of production of general anesthesia. However, if LVA current in other neurons is affected in a similar fashion, the ability of anesthetics to reduce seizure activity and produce analgesia may be related to reduction of this current.

\section{References}

Bean BP (1989) Classes of calcium channels in vertebrate cells. Annu Kev Physiol 51:367-384.

Berg-Johnsen J, Langmoen IA (1987) Isoflurane hyperpolarizes neurones in rat and human cerebral cortex. Acta Physiol Scand 130:679685.

Bossu J-L, Feltz A (1986) Inactivation of the low-threshold transient calcium current in rat sensory neurones: evidence for a dual process. J Physiol (Lond) 376:341-357.

Carbone E, Lux HD (1987) Kinetics and selectivity of a low-voltageactivated calcium current in chick and rat sensory neurones. J Physiol (Lond) 386:547-570.

Carbone E, Formenti A, Pollo A (1990a) Multiple actions of Bay K 8644 on high-threshold $\mathrm{Ca}$ channels in adult rat sensory neurons. Neurosci Lett 111:315-320.

Carbone E, Sher E, Clementi F (1990b) Ca currents in human neuroblastoma IMR 32 cells: kinetics, permeability and pharmacology. Pfluegers Arch 416:170-179.

Cavalie A, McDonald TF, Pelzer D, Trautwein W (1985) Temperature-induced transitory and steady-state changes in the calcium current of guinea pig ventricular myocytes. Pfluegers Arch 405:294-296. 
Coulter DA, Huguenard JR, Prince DA (1989a) Calcium currents in rat thalamocortical relay neurones: kinetic properties of the transient, low-threshold current. J Physiol (Lond) 414:587-604.

Coulter DA, Huguenard JR, Prince DA $(1989 \mathrm{~b})$ Characterization of ethosuximide reduction of low-threshold calcium current in thalamic neurons. Ann Neurol 25:582-593.

Eskinder H, Supan FD, Rusch NJ, Kampine JP, Bosnjak ZJ (1990) Effects of inhalational anesthetics on $\mathrm{L}$ - and $\mathrm{T}$-type $\mathrm{Ca}^{++}$channel currents in canine cardiac Purkinje cells. FASEB J 4:A4900.

Evers AS, Elliot WJ, Lefkowith JB, Needleman P (1986) Manipulation of rat brain fatty acid composition alters volatile anesthetic potency. $\mathrm{J}$ Clin Invest 77:1028-1033.

Firestone LL, Miller JC, Miller KW (1986) Appendix: tables of physical and pharmacological properties of anesthetics. In: Molecular and cellular mechanisms of anesthetics (Roth SH, Miller KW, eds), pp 455-470. New York: Plenum.

Franks NP, Lieb WR (1988) Volatile general anaesthetics activate a novel neuronal K* current. Nature 333:662-664.

Gage PW, Robertson B (1985) Prolongation of inhibitory postsynaptic currents by pentobarbitone, halothane and ketamine in CAI pyramidal cells in rat hippocampus. Br J Pharmacol 85:675-681.

Gross RA, MacDonald RL (1989) Activators of protein kinase C selectively enhance inactivation of a calcium current component of cultured sensory neurons in a pertussis toxin-sensitive manner. J Neurophysiol 61:1259-1269.

Haydon DA, Urban BW (1983) The effects of some inhalation anaesthetics on the sodium current of the squid giant axon. J Physiol (Lond) 341:429-450.

Haydon DA, Urban BW (1986) The actions of some general anaesthetics on the potassium current of the squid giant axon. J Physiol (Lond) 373:311-327.

Haydon DA, Requena J, Simon AJB (1988) The potassium conductance of the resting squid axon and its blockage by clinical concentrations of general anaesthetics. J Physiol (Lond) 402:363-374.

Herrington J, Stern RC, Evers AS. Lingle CJ (1990) Halothane reduces calcium currents in clonal $\left(\mathrm{GH}_{1}\right)$ pituitary cells. New York Academy of Sciences Conference on Molecular and Cellular Mechanisms of Alcohol and Anesthetics, Abstract W-6.

Himing LD, Fox AP, McCleskey EW, Olivera BM, Thayer SA, Miller $\mathrm{RJ}$, Tsien RW (1988) Dominant role of $\mathrm{N}$-type $\mathrm{Ca}^{2+}$ channels in evoked release of norepinephrine from sympathetic neurons. Science 239:57-61.

Holz GG IV, Dunlap K, Kream RM (1988) Characterization of the electrically evoked release of substance $P$ from dorsal root ganglion neurons: methods and dihydropyridine sensitivity. J Neurosci 8:463471.

Ikemoto Y, Yatani A, Imoto Y, Arimura H (1986) Reduction in the myocardial sodium current by halothane and thiamylal. Jpn J Physiol 36:107-121.

Kostyuk PG, Shirokov RE (1989) Deactivation kinetics of different components of calcium inward current in the membrane of mice sensory neurones. J Physiol (Lond) 409:343-355.

Kmjevic K, Puil E (1988) Halothane suppresses slow inward currents in hippocampal slices. Can J Physiol Pharmacol 66:1570-1575.

Kullmann DM, Martin RL, Redman SJ (1989) Reduction by general anaesthetics of group Ia excitatory postsynaptic potentials and currents in the cat spinal cord. J Physiol (Lond) 412:277-296.

Larrabee MG, Posternak JM (1952) Selective action of anaesthetics on synapses and axons in mammalian sympathetic ganglia. J Neurophysiol 15:91-110.
Llinas R (1988) The intrinsic electrophysiological properties of mammalian neurons: insights into central nervous system function. Science 242:1654-1664.

Llinas R, Yarom $Y$ (198I) Electrophysiology of mammalian inferior olivary neurones in vitro. Different types of voltage-dependent ionic conductances. J Physiol (Lond) 31 5:549-567.

Nakahiro M, Yeh JZ, Brunner E, Narahashi T (1989) General anesthetics modulate GABA receptor channel complex in rat dorsal root ganglion neurons. FASEB J 3:1850-1854.

Nicoll RA (1972) The effects of anaesthetics on synaptic excitation and inhibition in the olfactory bulb. J Physiol (Lond) 223:803-814.

Nicoll RA, Madison DV (1982) General anesthetics hyperpolarize neurons in the vertebrate central nervous system. Science 217:10551057.

Puil E, El-Beheiry H (1990) Anaesthetic suppression of transmitter actions in neocortex. Br J Pharmacol 101:61-66.

Richards CD (1983) Actions of general anaesthetics on synaptic transmission in the CNS. Br J Anaesth 55:201-207.

Ruppersberg JP, Rüdel R (1988) Differential effects of halothane on adult and juvenile sodium channels in human muscle. Pfluegers Arch 412:17-21.

Scholfield CN (1980) Potentiation of inhibition by general anaesthetics in neurones of the olfactory cortex in vitro. Pfluegers Arch 383:249255.

Schroeder JE, Fischbach PS, McCleskey EW (1990a) T-type calcium channels: heterogeneous expression in rat sensory neurons and selective modulation by phorbol esters. J Neurosci 10:947-951.

Schroeder JE, Fischbach PS, Mamo M, McCleskey EW (1990b) Two components of high-threshold $\mathrm{Ca}^{+}+$current inactivate by different mechanisms. Neuron 5:445-452.

Stecher PG, ed (1968) The Merck index: an encyclopedia of chemicals and drugs. Rahway, NJ: Merck.

Stern RC, Weiss CI, Steinbach JH, Evers AS (1989) Isoflurane uptake and elimination are delayed by absorption of anesthetic by the Scimed membrane oxygenator. Anesth Analg (Cleve) 69:657-662.

Suzuki S, Rogawski MA (1989) T-type calcium channels mediate the transition between tonic and phasic firing in thalamic neurons. Proc Natl Acad Sci USA 86:7228-7232.

Swandulla D, Carbone E, Schäfer K, Lux HD (1987) Effect of menthol on two types of Ca currents in cultured sensory neurons of vertebrates. Pfluegers Arch 409:52-59.

Takenoshita M, Steinbach JH (1990) Halothane blocks low-voltage activated calcium current in rat sensory neurons. Soc Neurosci Abstr 16:511.

Takenoshita M, Takahashi T (1987) Mechanisms of halothane action on synaptic transmission in motoneurons of the newborn rat spinal cord in vitro. Brain Res 402:303-310.

Tang C-M, Presser F, Morad M (1988) Amiloride selectively blocks the low threshold (T) calcium channel. Science 240:213-215.

Tokimasa T. Sugiyama K, Akasu T. Muteki T (1990) Volatile anaesthetics inhibit a cyclic AMP-dependent sodium-potassium current in cultured sensory neurones of bullfrog. $\mathrm{Br} J$ Pharmacol 101:190 192.

White G, Lovinger DM, Weight FF (1989) Transient low-threshold $\mathrm{Ca}^{2+}$ current triggers burst firing through an afterdepolarizing potential in an adult mammalian neuron. Proc Natl Acad Sci USA 86: $6802-6806$ 